\title{
Philosophy Between the Minds
}

Douglas Burnham

Nietzsche loved brief, teasing allegorical narratives. So, I have attempted one.

The Fourth Day: On the first day, the fool noticed simply that things change. Within the domain of the human, this is called 'history' in the broadest possible sense. Individuals are born, mature, have children, and die. Political, religious and economic systems develop and fall. Beliefs and values emerge and then are gone. Everything is History, said the fool.

On the second day, the fool observed that not everything changes. Those things that are eternal do not change, and those beings who create the changeable do not change. Indeed, change itself may be an illusion masking the eternal. Moreover, he saw that even in nature, some things either do not change at all, or change very slowly: an Empire may fall, but the stars and mountains and forests are still there. So, insofar as human beings are related in some way to the gods or the stars, then there will be constants within and across the domain of the human. For example, human beings have minds or souls, by means of which we can participate in the divine order of things. And, in so far as human beings are a part of nature, there may be aspects within the domain of the human that do not change. We can call this 'human nature'. Reasoning and experiencing, these don't change; pride, anger or love, these don't change.

By noon, the fool was reasoning thus: a number of distinctions arise, between those things that are in principle transient (within human history, we mean individual lives, political orders, beliefs and so forth), and those that do not change (the gods, the natural order as such including the basic character of the human). Likewise, there is a distinction between those aspects of human lives and even self-understanding that are governed by change (we will call this 'culture', the domain of activity) and those that do not, or at need not (philosophy, the domain of contemplation). Culture comprises those beliefs and values that come and go, although at any given time they may seem solid and given, and thus form 'what everybody knows' or 'common sense'. Philosophy is the striving for something permanent in the understanding of the human, of nature, and the ultimate meanings of both. Since philosophical truths are on principle remote from the sphere of culture and action, those human beings who live philosophical lives might sometimes make discoveries that they cannot reveal to culture. They thus write, if at all, esoterically. They see the history of philosophy as populated by their contemporaries, who speak to them in code across the centuries. Philosophy constructs bridges over abysses, high in the mountains, where most never tread. This, the fool thought, is the Philosophy of History.

By afternoon, the fool's thoughts changed. He observed the toil of the others in fields and battlefields, and wondered at the inefficacy of philosophical reason. Why should philosophy not be more like the blacksmith, producing new sturdy and sharp tools? Contemplation could transform activity; though culture may not be ready for this or that development yet, it soon will be. Esotericism remains necessary, as a temporary measure, to facilitate the philosophical transformation of culture.

In the evening, however, as the air cooled and the people gathered together around the fires, this esotericism all seemed so unnecessary. We are equal, and we are all 'in this together', the fool said, and felt able to say it aloud. Let us write clearly and for everyone; if the domain of activity is to be reformed, let us do so together. The sublime thought of the esoteric faded from his mind.

On the third day, the fool paused, thinking: those stars occasionally fall across the sky, the 
mountains contain marine fossils, what was once forest is now moorland, and even the gods seem suspiciously absent these days - maybe they were never more than a fable? Just briefly, the fool thought he was back to 'things change'. Swiftly, however, the fool realised that there was an important difference from that first day. The relationships between what formerly seemed changeable, and what did not, now appear quite complex. The eternal or natural aspects are not only subject to modification like everything else (albeit perhaps at a slower pace) but are also subject to modification by everything else. Within the human domain, this means: in accordance with their nature, human beings form culture, but also culture forms human nature. Everything is a double becoming, including philosophy and its truth. History, if it is anything at all other than a mere record of successive events, is the agonisingly slow liberation of the domain of action, certainly, but also the domain of contemplation. What is to be made free are the social and cultural conditions within which any thought or action are possible. We are historicists, we may even be relativists and postmoderns and other such names. This is the History of the Philosophy of History, so said the fool, and it is not at an end.

On the fourth day. ... But was there, will there be, a fourth day?

We all know what esoteric writing in philosophy means; and we can all agree, I think, that there are at least instances of esoteric writing in philosophical history. Before I had even heard of Leo Strauss, it was clear to me that Plato in the Parmenides was playing a sophisticated game of cat and mouse with his readers, whoever they may have been. Likewise it was hard to miss that in Hume's dialogues on religion, all the participants both are and are not at some point identifiable as Humeans. In each case, between the surface meaning and some underlying intent, available perhaps to insiders, there is so obvious a tension that even the surface meaning begins to crumble. No, what is at stake in Philosophy Between the Lines is not the existence of esoteric writing, but its prevalence, systematicity, and subsequent forgetting - along with a broadly political interpretation of these. Professor Melzer certainly shows the prevalence part, with an impressive barrage of examples and citations. Of course, if we are being strictly empiricist about this, all this evidence strung together (including the online appendix) is little more than a punctuation mark within the vast volume of western thought. But such doubts are beside the point: the evidence provided indicates a clear trend. Again, although I'm sure one could quibble about the details of this or that analysis, that is not the point, unless those quibbles become so numerous as to obscure the trend. Esotericism is - or is at least believed to be by other, later commentators ${ }^{1}$ - widespread within philosophy.

However, prevalence or trend is still not systematic. That is to say, it does not yet prove that esoteric writing is the normal mode for philosophy, across centuries, and thus that a kind of extended conversation is taking place, between the lines, so far beneath the notice of most readers that it is not even looked for. Now, I do not believe that Melzer has demonstrated this -- although I also do not feel confident to judge the matter here in a few thousand words. Nevertheless, only such a systematic esotericism would lead to the important conclusions about the nature of reason and history that Melzer (following Strauss) wants to maintain. If we, looking back over centuries of philosophy, only see the exoteric - the messages of which are crafted not to upset the apple cart we will (Melzer argues) have settled on the principle that reason is incapable of rising above the crass prejudices of its culture. The human mind is, for the most part, bound and gagged by its historical situation. Moreover, we will have lost sight of two distinct ways in which the life of contemplation might relate to the practical life of culture and history: an antagonistic relation,

1 This is a worry, to be sure. By its nature, the evidence has to be what commentators thought that some philosopher was up to. There is always the possibility, then, that esotericism is 'discovered' in texts, decades or centuries after they are written, the better to make them support 'our' cause.

Burnham -- 2 
typical of ancient thinkers, and a compatible relation, typical of more recent centuries, in which reason becomes practical and reforms the world. If, though, it is systematically the case that, under this surface meaning quite radical views can be found, then we have reason to reassess our analysis of the relationship between reason and history, in favour of a certain freedom of human rationality. Thereby also we might rediscover the ancient understanding of the contemplative life as distinct from the practical. The above account of the central argument may be very brief and leave out a great number of important details, but it is not, I hope, a caricature.

So, if I do not think I can say anything about the systematicity thesis, what can I say? The enemy here is historicism. Although Melzer sees his argument as moving from systematicity to the fallacy of historicism, he does not try to hide the fact that - in part at least - the motivation is the other way around. A kind of intuitive repugnance at historicism drives the quest to discover esotericism. But what is historicism? Historicism, first of all, is a position defined primarily by its opponents (Popper, Strauss, etc.) -- an accusation and not a badge -- and therefore demonstrates more underlying variety than might be expected. There are certainly very few philosophers who say 'I call myself a Historicist'. Nevertheless, let us sketch out provisionally a position that we can use for the sake of argument. Broadly, historicism is the thesis that all cultural products can only properly be understood within their historical context - indeed, are themselves indirect products of that context -- and that this context is constantly shifting. Shakespeare may seem to be our 'contemporary', but such a Shakespeare is more our sock puppet than a genuine 'universal genius'. As with esotericism, there is no doubt that this thesis is at least partially true. The specifically political and religious dimension of Macbeth (largely related to the ascension of James I) - without which the 'Scottish Play' would probably never have been written - is largely lost on a modern audience, although the play is nonetheless widely performed and appreciated. Although those dimensions can be reconstructed by a scholar, that reconstruction is likely to mean that he or she appreciates the play less in performance. For our purposes, the history of historicism begins in the $18^{\text {th }}$ Century, as a proto-romantic response to zealous neo-classicism. I am thinking, for example, of Herder, for whom Shakespeare is the authentic artist precisely because he does not cravenly try to imitate ancient tragedy like the French, but instead writes a drama that emerges organically from English soil. ${ }^{2}$ A few decades later and historicism and its sister, hermeneutics, are riding high partly because of Hegel. ${ }^{3}$ Historicism later takes on a pointed political dimension, most famously in Marx: ideas are a product of social and economic conditions; there is little point in intellectuals pretending that they can think outside their environment; thought, like the people who think, can only be liberated if the social and economic conditions are transformed. ${ }^{4}$ This notion eventually acquired the name 'historical materialism'. This was and remains the high point of historicist thought, and for practical purposes the only innovation 150 years later is that postmodernists ${ }^{5}$ have become sceptical of the possibility of any such transformation. Now, as I will show below, this sketch of historicism is in fact a caricature, but it will have to serve for the moment.

Nietzsche occupies a curious position in the debates about esotericism. On the one hand he is, of course, among the poster boys of historicism. Above all, there are the analyses found most famously in The Genealogy of Morality concerning the 'breeding' of human affects and modes of thought. ${ }^{6}$

2 Herder. Shakespeare. Trans. Moore. Princeton, 2008. The original was published in 1773. The connection of historicism with nationalism also begins in such analyses.

3 It is worth noting that 'hermeneutics', although certainly dealing with historical phenomena as a problem, is not intrinsically historicist. Thus, in Truth and Method Gadamer feels he has to overcome much of $19^{\text {th }}$ Century hermeneutics.

4 This is the substance of the opening pages of The German Ideology. Prometheus, 1976.

5 Whoever they are.

6 Treatise two, section 2; Treatise 3, section 21 - to list only the most obvious. See also Beyond Good and Evil, section 199, and Twilight of the Idols, 'Improvers of Humanity'.

Burnham -- 3 
The implication is, as it is expressed above in my aphorism, that there is a double becoming, a reverse influence of culture back upon human nature. There is little or nothing that is 'ahistorical', the human having been made, unwittingly for the most part and often disastrously, by the human. Nietzsche is thus famously dismissive of anachronism in morality. ${ }^{7}$ Here too belong his many critiques of the metaphysical neutrality of reason ${ }^{8}, \operatorname{logic}^{9}$, scientific method ${ }^{10}$ and even the notion of truth itself. ${ }^{11}$ All of these analyses suggest that those presumably a- or super- historical phenomena or methods are anything but. Rather than tools neutral to historical forces, Nietzsche tends to analyse them as tools of such forces. More specifically, Nietzsche as a scholar of ancient language and literature was convinced that the emotional life of the Greeks was essentially different, rather than just being the same affective system under different conditions. ${ }^{12}$

On the other hand, Nietzsche is also among the saints of the idea of exceptionalism, the thesis that certain human beings are able to rise above their conditions and in some sense speak and indeed act beyond them, primarily but not exclusively about moral or political matters. This is the explicit reason Nietzsche wrote 'Philosophy in the Tragic Age of the Greeks,' and the idea is found prominently again in the second Untimely Meditation, section $2 .{ }^{13}$ Nietzsche fondly attributes the idea of the 'republic of genius' to Schopenhauer. ${ }^{14}$ A similar notion is found in Nietzsche's later writings, for example, in the discussion of Jesus in The Antichrist ${ }^{15}$ or in the metaphor of Zarathustra's abandonment of his home for a cave in the mountains. ${ }^{16}$ In both of those cases, the analysis is of a mind so untimely as to be incomprehensible to its hide-bound contemporaries, and finding its proper audience elsewhere (in disciples, although Jesus was poorly served by his) and elsewhen.

We owe these ideas at least partially to the $19^{\text {th }}$ Century's romantic fondness for the hero as autonomous but also misunderstood and alone (just think of Byron's Manfred or Carlyle's On Heroes, the popular image of Beethoven, passages in Emerson's Representative Men, Wagner's heroes, and the long shadow that Napoleon cast over the century). Do note, though, how curious it is that romanticism should be in part responsible both for the thesis of exceptionalism and of historicism. In fact, the idea of exceptionalism is needed precisely because of historicism. Without the latter, there would be nothing to be an exception to. For Enlightenment thought, with its vehemently anti-historicist models of reason and language, and with (as Melzer sees it) its compatibilist account of the relation of theory and practice, exceptionalism is unnecessary. The enemy is human nature, not culture, and that enemy will be vanquished by concepts like temperance and the formation of good habits, not by a quasi-religious transformation into an exception. Individuals (or classes) might vary as to their capacity for reason and for example in their ability to control their passions, but this variance is natural to the human. ${ }^{17}$ By contrast, Romantic

7 The thesis of the discontinuity of moral concepts is found already in The Birth of Tragedy and in the third Untimely Meditation. It then also appears, much later, in the first treatise of Genealogy. There he is thinking specifically of altruism, and has his old friend Rée and probably Spencer in his sights.

8 E.g. Twilight of the Idols, 'Reason in Philosophy'.

9 E.g. Beyond Good and Evil, section 3.

10 E.g. The Gay Science, section 344, or Genealogy, Treatise 3, sections 23-4.

11 E.g. Beyond, section 34, or Twilight, 'How the true world at least became a fable'.

12 See the two 'Eris's in 'Homer's Contest', or foolishness versus sin at Genealogy, Treatise 2, section 23. See also the alienness of the Greeks professed at Twilight, 'What I owe the ancients', section 2.

13 Indeed, this idea is precisely the reason why those four short books are called 'untimely'.

14 See both the second and third Untimely Meditation.

15 'This faith also does not formulate itself - it lives, it fights against formulas' (section 32).

16 In addition, Nietzsche talks frequently about the 'exception' in just this way, e.g. Daybreak, section 442, Gay Science, sections 3 and 76, or Ecce Homo, 'Why I am a Destiny', section 5.

17 I feel uncomfortable talking in such generalities about the 'Enlightenment', 'Romanticism' or the 'Ancient World'. I think these claims are warranted only insofar as we are talking about broad trends, and we do not forget the many 
exceptionalism - and something similar is true in Nietzsche - involves what is to all intents and purposes a different species.

On the other hand, in Strauss and Melzer's characterisation of the ancient world as holding a broadly antagonistic view regarding the relationship of the active and contemplative lives, historicism is again assumed, albeit only for the vita activa. The philosopher, through a transformation of his or her way of living, and wresting free of the doxa of the city, becomes an exception. The esoteric-writing thesis thus assumes historicism, but somehow claims that it doesn't apply to us. What is this 'somehow'? To my mind, one key thing that Melzer's theoretical chapter (ch. 3) lacks is a sustained account of how exceptionalism - the vita contemplativa - is possible. Without a solution to this, exceptionalism in any of its guises looks like wishful thinking. Can Nietzsche help us to make some progress here?

The temptation is to discount both sides of Nietzsche's analysis as residues of romanticism; this would be a mistake, not least because Nietzsche himself spear-heads the late-19th Century rejection of romantic excess. Nietzsche's mindfulness for historical nuance and difference means that his 'exceptions' - and certainly also the 'future' exception that is the Übermensch - need analysis as something other than Byronic heroism. Likewise, that there are such exceptions entails that his historicism is not as one-sided as that which Melzer decries. In terms of my cod-Nietzsche aphorism, that is, we can identify Nietzsche himself with none of the stages through which the fool passes. Instead, I suggest, Nietzsche represents the fourth day.

Let us return to the above account of historicism. In my experience, the interpretations of ancient philosophy by those writers labelled historicist or postmodern are, in fact, much more radical and interesting than those given by other interpretative traditions. I'm thinking of Heidegger ${ }^{18}$, Gadamer $^{19}$, Derrida ${ }^{20}$, Ricoeur ${ }^{21}$, Foucault ${ }^{22}$ or Badiou ${ }^{23}$, in particular. Now, why should this be the case? Well, the above description of historicism was a confessed caricature because it makes (at least) two assumptions, which are also shared by the fool on all three days. But these assumptions, perhaps more than any others, have been philosophically challenged over the past two centuries. Once we remove these two unfortunate assumptions, historicism - including Nietzsche's - is revealed as not so one-sided, and as having resources that will be useful on the fourth day. This is why these philosophers are capable not only of accepting the existence of, but also of unearthing, 'ideas' that diverge from the standard ways of reading.

First, the above description of historicism assumes as fundamental the distinction between individual and group. According to this distinction, either we claim that the group does not exist, except as the assemblage of autonomous individuals ${ }^{24}$, or the distinction collapses and the individual is simply a function of the group. This assumption, although characteristic of a great

who do not fit the mould.

18 On the very first page of Being and Time, it is clear that the only philosopher Heidegger considers truly contemporary is ... Plato. Volumes of lectures are devoted to readings of pre-Socratics and especially Aristotle. Properly understood, the 'destruction' of the history of ontology is not an entirely negative operation; it rather uncovers the thought implicit but occluded in that history.

19 Gadamer. Dialogue and Dialectic. Yale, 1983.

20 e.g. 'Plato's Pharmacy' in Dissemination. Athlone, 1993.

21 I'm thinking of the uses of Aristotle in the work on metaphor (The Rule of Metaphor. $3^{\text {rd }}$ ed. Routlege, 2003) and the work on narrative (Time and Narrative. 3 vols. Chicago, 1984).

22 As in the studies of Epicureanism and Stoicism in his early eighties lectures, collected as The Hermeneutics of the Subject, Picador, 2005.

23 Again, Plato in Being and Event. Bloomsbury/Continuum, 2007.

24 The locus classicus of this idea is Bentham, Principles of Morals and Legislation. Dover, 2007. vol. 1 p. 3. It should be noted that the term 'individual' hides an enormous range of definitions and measurements. 
many philosophical traditions, is not one that can be laid at the feet of a sophisticated historicism. What is missing is any sense of a dynamic relationship - which is odd, since precisely a dynamism of this type is one of Hegel's greatest and most famous ideas. ${ }^{25}$ A theory of dynamic relationship would claim, among other things, that individualism is not an all-or-nothing affair, and that a whole set of processes contribute to the emergence of a recognisable individual and indeed of the type social group within which such an individual could be recognised. ${ }^{26}$

Second, the caricature takes, again as fundamental, the equation of thinking or belief with consciousness $^{27}$, and thus with what I may say or write, or choose not to say or write. ${ }^{28}$ Again, this assumption is very common, but not among those we are calling historicists. Rather than relying upon the distinction between expressed and unexpressed, many so-called historicists or postmodernists can also talk about the 'unconscious' very broadly speaking. ${ }^{29}$ By this is meant thought that is not simply present to or having its origin in transparent consciousness, and indeed that does not in the first instance 'belong' to an individual mind, but which is in some other way found and operative in their individual or collective behaviours, especially the use of language. ${ }^{30}$

Now, consider for example the Strauss and Melzer account of vita contemplativa as a different way of living in the ancient world. As we noted above, this in turn requires a story concerning one's wresting free of the illusions of the tribe, e.g. the ascent from the cave. In other words, it assumes a historicism -- we are not 'pure minds', as Melzer notes -- but then pursues only a fully apolitical, individual solution to that historicism. But because postmodernism does not take individualism for granted, it can offer a much more intriguing, and politically useful, account of this 'wresting free'. In particular, it can talk about the role of institutions, or other types of political and social organisation, in the development of the philosophical mind. A good example would be a school, the Academy or Lyceum, a form of pedagogy not limited to an individual's encounter with an esoteric text. ${ }^{31}$ Indeed, with Nietzsche, we can talk about cultural life self-transcending itself in the exception. ${ }^{32}$ Likewise, when Strauss and Melzer defend reason, it tends to be pictured as a reason that is a conscious instrument in the hands of an individual who then, in a sovereign act of will, chooses whether to speak. Here, we find no sense of writing and indeed living as practices, as a working-out-of thought and of life, or otherwise as part of the 'wresting oneself free'. ${ }^{33}$ Ancient Greek and Roman philosophers were one and all concerned with the details of life practices eating, sleeping, hygiene, routine - and with character and virtue considered not as states but as practices. ${ }^{34}$ These did not emerge from a philosophical system as its results or supplements; these practices comprise the philosophical life. Likewise, without such an account, we can only conceive

25 The 'master and slave' dialectic in The Phenomenology of Mind being only the most obvious. Here, also, Arendt's The Human Condition (Chicago, 1958) merits mention.

26 These processes are the important thing, and many philosophers thus see the emergence of an individual per se as an effect and not in itself an end.

27 The locus classicus is of course Descartes for whom the existence of the self, thinking, and consciousness were all equivalent.

28 In $20^{\text {th }}$ Century criticism, this is sometimes called the 'Intentional Fallacy' - the assumption that what is found in the work must at some point have been a conscious intention in the author.

29 A dangerous word. One of the thinkers relevant here is Freud, but he by no means the only one.

30 With the exception of some phenomenological traditions, 'consciousness' is among the least used words in continental philosophy. Although we tend to anachronistically read ancient thought as a philosophy about consciousness, this is probably an error.

31 Other examples of institutions whose relationship to the maturation of philosophical reasoning are not confined to the preliminaries, nor are simply barriers, might include marriage, the church, friendship, the library, etc.

32 Nietzsche's theme of decadence or corruption often carries this meaning; see e.g., Gay Science, section 23.

33 I believe Melzer is aware of these - they are gestured toward in Philosophy Between the Lines - but they are not made central and they're certainly not developed.

34 We should add to this list 'skepticism', a theme that Melzer following Strauss develops in chapter 10.

Burnham -- 6 
a 'school of thought' as the sum of the ideas expressed by its representatives, rather than seeing it as a movement that bears and makes thought possible. Similarly, it would make no sense to talk about 'Greek philosophy' or 'German philosophy' otherwise than as a handful of themes upon which a number of figures agree - the concept of a philosophical tradition as itself something serving as a medium of thought is lost. ${ }^{35}$

Historicism or postmodernism, absolved of our original caricature, is still not a badge. However, I also think it is no longer an obvious straw man, to be easily knocked over and then ignored. Historicism includes intellectual resources for analysing, not the manner in which historical circumstances bound and gag thought, but how they function within a dynamic relationship with the emergence of thought. Although I am not even convinced that the antagonistic relation of contemplation and practice is the correct way to understand ancient thought, to even ask that question requires that we understand much more about how contemplation emerges against the backdrop of the latter. To my mind, the resources of historicism can only help us here. The fourth day is a return to neither the second (the theory of the necessity of esotericism, including its forgetting), nor the third (historicism in its caricature version, which at best leads to some hope for future, revolutionary redemption). Instead, I suggest that we look for the fourth day in a rather more modest place: a patient understanding and construction of the conditions (including material conditions) for, and the practices of, thought.

35 Indeed, rejecting the caricature, we can in a Heideggerian vein talk about the way in which a language is not simply a tool for the representation of ideas, but itself thinks. 